\title{
ANALISIS QUALITY OF SERVICE MENGGUNAKAN METODE HIERARCHICAL TOKEN BUCKET (STUDI KASUS: FTI UKSW)
}

\author{
Yoppy B Pello ${ }^{1}$, Rissal Efendi ${ }^{2}$ \\ ${ }^{1,2}$ Fakultas Teknologi Informasi, Program Studi Teknik Informatika, Universitas Kristen Satya Wacana \\ Email: ${ }^{1}$ ypello24@gmail.com, ${ }^{2}$ rissal.efendi@uksw.edu
}

(Naskah masuk: 19 Agustus 2021, diterima untuk diterbitkan: 4 September 2021)

\begin{abstract}
Abstrak
Fakultas Teknologi Informasi Universitas Kristen Satya Wacana merupakan salah satu fakultas yang telah berkembang, perkembangan teknologi informasi menyebabkan tingginya permintaan terhadap tenaga kerja yang handal serta mempunyai kemampuan di dalam bidang teknologi informasi. Salah satu faktor pendukung perkembangan yaitu dengan adanya teknologi dapat membuat semua proses pertukaran data menjadi lebih cepat. Seiring dengan berjalannya waktu, proses pertukaran data tidak diimbangi dengan mutu layanan jaringan sehingga menyebabkan bandwidth yang tersedia tidak digunakan secara optimal. Solusi dari masalah ini dengan adanya Quality of Service, bandwidth yang tadinya kurang maksimal dapat di atasi dengan metode Hierarchical Token Bucket karena metode ini dapat mengelompokkan queue menjadi lebih terstruktur. Penelitian ini bertujuan untuk menganalisa jaringan WLAN yang ada di FTI UKSW dengan menggunakan aplikasi Wireshark sebagai tools utama agar dapat mengukur parameter QoS. Hasil QoS yang di analisa selama 30 detik mendapatkan hasil yang sangat memuaskan dengan metode HTB. Untuk hasil pengukuran total, delay sebesar $23.70 \mathrm{~m} / \mathrm{s}$, jitter $12.92 \mathrm{~m} / \mathrm{s}$, packet loss $0 \%$, dan throughput $100 \%$. Kemudian untuk rata-rata delay sebesar $0.005868272 \mathrm{~m} / \mathrm{s}$, dan rata-rata jitter $0.00319989 \mathrm{~m} / \mathrm{s}$.
\end{abstract}

Kata kunci: $Q o S, H T B$, Analisa, Bandwidth, WLAN

\section{QUALITY OF SERVICE ANALYSIS USING THE HIERARCHICAL TOKEN BUCKET METHOD (CASE STUDY: SWCU FTI)}

\begin{abstract}
The Satya Wacana Christian University Faculty of Information Technology is one of the faculties that has developed, the development of information technology causes a high demand for reliable and skilled workers in the field of information technology. One of the factors supporting the development is that technology can make all data exchange processes faster. Over time, the data exchange process is not matched with the quality of network services, causing the available bandwidth to not be used optimally. The solution to this problem is the existence of Quality of Service, the previously less than optimal bandwidth can be overcome with the Hierarchical Token Bucket method because this method can group queues into a more structured way. This study aims to analyze the WLAN network in the SWCU FTI using the Wireshark application as the main tool to measure QoS parameters. QoS results were analyzed for 30 seconds to get very satisfactory results with the HTB method. For total measurement results, the delay is $23.70 \mathrm{~m} / \mathrm{s}$, jitter is $12.92 \mathrm{~m} / \mathrm{s}$, packet loss is $0 \%$, and throughput is $100 \%$. Then the average delay is $0.005868272 \mathrm{~m} / \mathrm{s}$, and the average jitter is $0.00319989 \mathrm{~m} / \mathrm{s}$.
\end{abstract}

Keywords: QoS, HTB, Analysis, Bandwidth, WLAN

\section{PENDAHULUAN}

Fakultas Teknologi Informasi Universitas Kristen Satya Wacana merupakan salah satu fakultas yang memiliki sistem kompleks yang terdiri dari banyak jurusan, dan bagian penting lainnya. Dengan ruang lingkup fakultas yang besar, maka penerapan sistem informasi di pusat akan memberatkan server utama. Sekalipun proses sistem informasi tersebut dibagi ke dalam beberapa jurusan dan juga bagian penting lainnya, maka akan ada banyak sekali sistem informasi dengan berbagai program sistem operasi yang sedang berjalan maupun kinerja jaringan komputer atau layanan dengan kelebihan dan kekurangannya masing-masing.

Perkembangan teknologi informasi dan komunikasi di Indonesia semakin mempermudah setiap orang dalam melakukan pekerjaan di berbagai bidang, diantaranya dalam bidang pendidikan. Salah satu perkembangan teknologi informasi dan 
komunikasi adalah internet. Internet saat ini merupakan satu hal yang penting dalam sebuah perusahaan atau instansi. Dengan adanya jaringan internet, kegiatan komunikasi untuk mendapatkan informasi menjadi lebih mudah [1]. Seiring dengan meningkatnya jumlah pengguna internet, membuat lalu lintas pada jaringan semakin kompleks [2]. Sehingga solusi yang terbaik untuk mengatasi masalah ini yaitu dengan melakukan manajemen bandwidth [3].

Tetapi terdapat beberapa kendala dan permasalahan pada manajemen bandwidth, seperti permasalahan kegagalan dan keterlambatan dalam proses pengiriman data dikarenakan padatnya traffic pada jalur internet tersebut mengakibatkan banyaknya pengguna dari jaringan internet terhadap bandwidth yang dimiliki dan bisa juga karena tidak adanya pengaturan atau pembagian bandwidth [4]. Sehingga optimalisasi penggunaan bandwidth adalah salah satu keharusan admin jaringan agar penggunaan bandwidth dapat digunakan secara optimal dan user mendapatkan pelayanan yang baik.

Quality of Service (QoS) adalah layanan untuk mengatur dan mengelola pertukaran lalu lintas data dalam mengelola bandwidth di dalam jaringan. Sehingga kemampuan jaringan dapat digunakan secara optimal. Adapun parameter Quality of Service adalah Delay, Jitter, Packet loss, dan Throughput [5].

Hierarchical Token Bucket (HTB) adalah antrian classfull dimana antrian ini mempunyai fungsi untuk mengerjakan bermacam-macam jenis traffic sehingga HTB dapat mengelompokkan queue menjadi lebih terstruktur seperti (parent-child) atau (child-child) [6].

Penelitian terkait Penerapan Manajemen Bandwidth Menggunakan HTB dengan Router Mikrotik telah dilakukan. Menurut Aji Diyantoro dan Noor Hapip Haekal dalam penelitian ini menjelaskan bahwa router akan menjadi perangkat utama dalam melakukan proses pengiriman paket data melalui jaringan internet sehingga proses ini juga digunakan dalam melakukan pengelolaan lalu lintas jaringan termasuk manajemen bandwidth. Dengan adanya Hierarchical Token Bucket menjadikan dalam membuat queue di Mikrotik Routerboard menjadi lebih terstruktur dengan melakukan pengelompokan bertingkat [7].

Perkembangan jaringan yang semakin ramai mengharuskan layanan sistem informasi menjadi lebih cepat, sehingga membuat Shiha Budin dan Imam Riadi menulis tentang Traffic Shaping dengan Metode Hierarchical Token Bucket pada Jaringan Nirkabel. Penelitian ini menjelaskan bahwa Traffic Shaping dengan Metode HTB bisa membagi trafik agar lebih teliti, sehingga bandwidth yang tidak dipakai dapat di optimalkan oleh user lainnya. Hasil Traffic Shaping dengan metode HTB mendapatkan hasil rata-rata 3,75 sehingga dapat di kategorikan memuaskan, di bandingkan tidak menggunakan traffic shaping dengan hasil rata-rata 2,25 yang di kategorikan sedang [8].

\section{METODE PENELITIAN}

\subsection{Quality of Service}

QoS atau Quality of Service adalah metode pengukuran dimana metode ini digunakan untuk menentukan kapabilitas jaringan, seperti aplikasi jaringan, host, atau router untuk menyediakan layanan jaringan yang lebih baik dan terencana sesuai dengan kebutuhan layanan. Adapun parameter di dalam QoS adalah Delay, Jitter, Packet loss, serta Throughput. QoS juga membantu user agar lebih mampu di dalam mendapatkan performa yang lebih cepat dari aplikasi berbasis jaringan [9]. Nilai dari Quality of Service menurut standard kualitas jaringan dari TIPHON (Telecommunications and Internet Protocol Harmonization Over Network) [10] di jelaskan di Tabel 1.

\begin{tabular}{ccc}
\multicolumn{3}{c}{ Tabel 1. Index Quality of Service } \\
\hline Nilai & Persentase & Index \\
\hline $3,8-4$ & $95-100 \%$ & Sangat Memuaskan \\
$3-3,79$ & $75-94.75 \%$ & Memuaskan \\
$2-2,99$ & $50-74,75 \%$ & Sedang \\
$1-1,99$ & $25-49,75 \%$ & Jelek \\
\hline
\end{tabular}

Nilai persentase pada Tabel 1 dipakai untuk memastikan kapabilitas pada jaringan. Menurut index QoS dengan mengukur rata-rata nilai yang di dalamnya terdapat parameter Delay, Jitter, Packet loss, dan Throughput.

\section{a. Delay}

Adalah total waktu yang tertunda akibat suatu paket yang di akibatkan oleh proses transmisi dari satu titik ke titik yang lain ke tempat yang dituju. Di jelaskan di Tabel 2.

\begin{tabular}{ccc}
\multicolumn{3}{c}{ Tabel 2. Delay } \\
\hline Degradasi & Besar Delay & Index \\
\hline Sangat Memuaskan & $<150 \mathrm{~m} / \mathrm{s}$ & 4 \\
Memuaskan & $150 \mathrm{~m} / \mathrm{s}-300 \mathrm{~m} / \mathrm{s}$ & 3 \\
Sedang & $300 \mathrm{~m} / \mathrm{s}-450 \mathrm{~m} / \mathrm{s}$ & 2 \\
Jelek & $>450 \mathrm{~m} / \mathrm{s}$ & 1 \\
\hline
\end{tabular}

b. Jitter

Adalah variasi atau perubahan delay waktu kedatangan paket. Jitter juga diartikan sebagai gangguan pada komunikasi digital atau analog yang disebabkan karena perubahan sinyal. Di jelaskan di Tabel 3.

\begin{tabular}{ccc}
\multicolumn{3}{c}{ Tabel 3. Jitter } \\
\hline Degradasi & Peak Jitter & Index \\
\hline Sangat Memuaskan & $0 \mathrm{~m} / \mathrm{s}$ & 4 \\
Memuaskan & $0 \mathrm{~m} / \mathrm{s}-75 \mathrm{~m} / \mathrm{s}$ & 3 \\
Sedang & $75 \mathrm{~m} / \mathrm{s}-125 \mathrm{~m} / \mathrm{s}$ & 2 \\
Jelek & $125 \mathrm{~m} / \mathrm{s}-225 \mathrm{~m} / \mathrm{s}$ & 1 \\
\hline
\end{tabular}

c. Packet loss 
Adalah suatu kondisi dimana menunjukkan jumlah total paket yang hilang. Packet loss juga diartikan sebagai kegagalan transmisi paket data untuk mencapai tujuannya, yang disebabkan oleh tabrakan di dalam jaringan. Di jelaskan di Tabel 4 .

\begin{tabular}{ccc}
\multicolumn{3}{c}{ Tabel 4. Packet loss } \\
\hline Degradasi & Packet loss & Index \\
\hline Sangat Memuaskan & $0-2 \%$ & 4 \\
Memuaskan & $3-14 \%$ & 3 \\
Sedang & $12-24 \%$ & 2 \\
Jelek & $>25 \%$ & 1 \\
\hline
\end{tabular}

\section{d. Throughput}

Adalah kemampuan suatu jaringan di dalam melakukan proses pengiriman data biasanya throughput selalu disamakan dengan bandwidth dalam kondisi yang sebenarnya. Throughput dapat di ukur dalam bytes/s. Di jelaskan di Tabel 5.

\begin{tabular}{ccc}
\multicolumn{3}{c}{ Tabel 5. Throughput } \\
\hline Degradasi & Throughput & Index \\
\hline Sangat Memuaskan & $100 \%$ & 4 \\
Memuaskan & $75 \%$ & 3 \\
Sedang & $50 \%$ & 2 \\
Jelek & $<25 \%$ & 1 \\
\hline
\end{tabular}

Rumus untuk menghitung Throughput [11] adalah :

Throughput $=$ Packet Received $(k b)$

\section{Time Transmitted (s)}

\subsection{Hierarchical Token Bucket}

HTB adalah cara untuk membatasi trafik pada setiap klasifikasinya sehingga hal ini membuat bandwidth yang tidak digunakan dapat dipakai oleh prioritas yang lain. Lalu terdapat tiga tipe class dalam HTB, yaitu: root, inner, dan leaf. Root class yang berada paling atas memprioritaskan semua traffic harus melewati class ini. Inner class memiliki parent class dan child class. Sedangkan leaf class, yang berada dalam class paling dasar dari layer harus lebih tinggi melalui klasifikasi yang harus digunakan melalui filter, sehingga dapat membedakan jenis traffic dan prioritasnya [12].

\subsection{Wireshark}

Wireshark adalah tools atau aplikasi Network Analyzer yang biasa digunakan oleh Network Administrator sebagai pemecahan masalah jaringan dan penganalisis kualitas jaringan yang di dalamnya terdapat berbagai jenis data dari internet. Kemudian wireshark juga dipakai untuk sniffing atau mengambil data dan informasi secara illegal. Wireshark juga mempunyai berbagai macam fitur yang di dalamnya terdapat fitur display filter language [13].

\subsection{Bandwidth}

Bandwidth adalah kapasitas atau daya tampung kabel Ethernet agar bisa melewati traffic paket data dalam jumlah tertentu. Luas atau lebar cakupan frekuensi yang digunakan oleh sinyal dalam proses transfer data dihitung dalam bytes/s. Bisa juga diartikan sebagai lebar cakupan frekuensi yang dipakai oleh sinyal dalam medium transmisi [14].

\subsection{Tahapan Penelitian}

Cisco telah menghasilkan sebuah siklus perencanaan jaringan [15]. Di dalam penelitian ini dapat dibagi ke dalam 6 (enam) tahap yaitu sebagai berikut: 1. Prepare, 2. Plan, 3. Design, 4. Implement, 5. Operate, 6. Optimize.

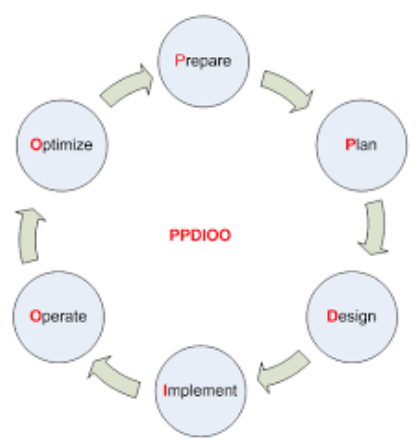

Gambar 1. Alur Tahapan PPDIOO

Tahapan penelitian pada Gambar 1 di jelaskan seperti ini :

Tahapan Pertama

Prepare : Mengidentifikasi masalah merupakan langkah awal dalam melihat permasalahan QoS yang berkaitan dengan metode HTB. Perumusan masalah yang di ambil dalam penelitian ini meliputi :

1. Data diambil hanya di Fakultas Teknologi Informasi Universitas Kristen Satya Wacana.

2. Menggunakan aplikasi wireshark sebagai network analyzer.

3. Untuk monitoring jaringan harus terhubung dengan jaringan WLAN FTI UKSW.

Tahapan Kedua

Plan : Pada tahap ini dilakukan pengumpulan data acuan seperti buku, jurnal, dan sumber lain untuk mendukung analisa QoS dengan metode HTB.

\section{Tahapan Ketiga}

Design : Tahap ini dilakukan pembuatan desain topologi jaringan FTI UKSW yang lama dan mengalokasikan bandwidth di setiap bagian, kemudian dilakukan pengembangan.

\section{Tahapan Keempat}

Implement: Pada tahap ini akan di lakukan proses yang sudah di rencanakan dan di desain sebelumnya. 
Tahapan Kelima

Operate : Pada tahap ini akan dilakukan penentuan alokasi manajemen bandwidth dengan metode HTB agar dapat berjalan sesuai dengan prosedurnya.

Tahapan Keenam

Optimize : Di tahap terakhir ini akan dilakukan evaluasi QoS dengan metode HTB yang telah dikembangkan, serta membandingkan dengan hasil data sebelum dan sesudah menggunakan Quality of Service.

\section{HASIL DAN PEMBAHASAN}

\subsection{Perancangan Topologi Jaringan FTI UKSW}

Pada tahap penelitian ini sebelum melakukan perancangan bandwidth Hierarchical Token Bucket, tahap selanjutnya yaitu mendesain topologi jaringan di jelaskan pada Gambar 2.

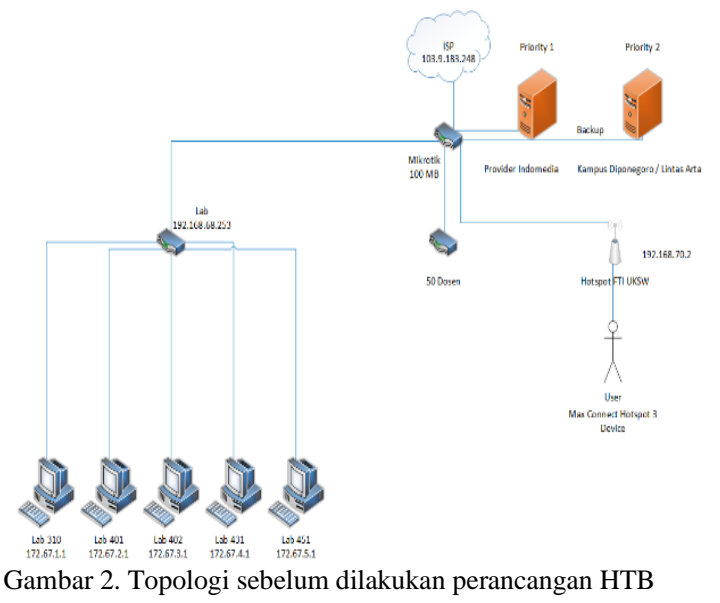

Gambar 2 adalah topologi FTI UKSW sebelum dilakukan metode HTB yang terdiri dari jaringan utama, yaitu jaringan ISP (103.9.183.248), Lab (192.168.68.253), dan Hotspot (192.168.70.2). Adapun alokasi bandwidth seperti Tabel 6.

\begin{tabular}{|c|c|}
\hline \multicolumn{2}{|l|}{ Tabel } \\
\hline Jaringan & Bandwidth \\
\hline Mikrotik & $100 \mathrm{MB}$ \\
\hline $\mathrm{Lab}$ & $30 \mathrm{MB}$ \\
\hline Dosen & $50 \mathrm{MB}$ \\
\hline Hotspot & $20 \mathrm{MB}$ \\
\hline
\end{tabular}

\subsection{Perancangan Manajemen Bandwidth HTB}

Sesudah dilakukan perancangan topologi jaringan kemudian dilakukan perancangan manajemen bandwidth HTB Di jelaskan pada Gambar 3.

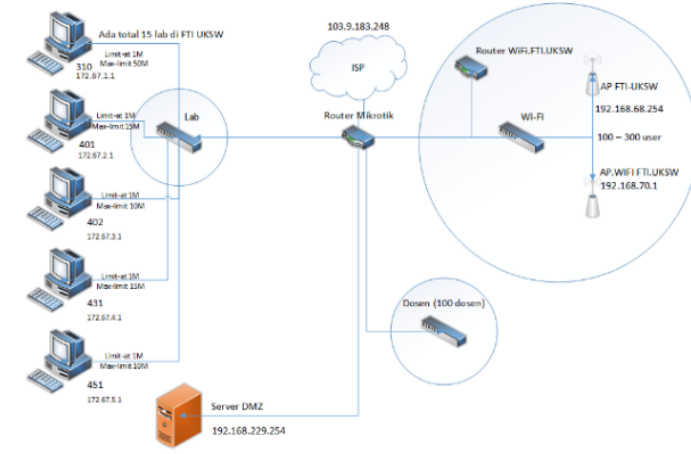

Gambar 3. Topologi jaringan sesudah dilakukan perancangan HTB

Gambar 3 adalah topologi jaringan FTI UKSW sesudah dilakukan perancangan HTB. Dalam topologi jaringan di atas, jaringan lab yang terdiri dari 15 lab mempunyai kecepatan jaringan yang berbedabeda karena tergantung dari kebutuhan dan pemakaian user. Terdapat juga server DMZ yaitu mekanisme untuk melindungi sistem internal dari serangan hacker atau pihak lain yang ingin memasuki sistem tanpa memiliki hak akses. Jaringan lab, dosen, dan Wi-Fi merupakan penggabungan group dari seluruh jaringan di FTI UKSW. Bandwidth yang di miliki oleh jaringan FTI UKSW sebelumnya adalah 100 Mbps kemudian ditingkatkan sebesar 500 Mbps. Untuk batas maksimal user Wi-Fi di FTI UKSW hanya bisa menampung 100-300 user. Penerapan manajemen bandwidth HTB, menjadikan user jaringan Wi-Fi mendapatkan akses full bandwidth sebesar 40 Mbps.

\subsection{Hasil Pengukuran Parameter QoS}

Tabel 7. Parameter-parameter QoS di FTI UKSW

\begin{tabular}{ccc}
\hline Parameter QoS & Hasil Pengukuran Total & Index \\
\hline Delay & $23.70 \mathrm{~m} / \mathrm{s}$ & 4 \\
Jitter & $12.92 \mathrm{~m} / \mathrm{s}$ & 3 \\
Packet loss & $0 \%$ & 4 \\
Throughput & $100 \%$ & 4 \\
\hline
\end{tabular}

Berdasarkan pada data Tabel 7 di atas, maka dapat di simpulkan nilai Delay sebesar $23.70 \mathrm{~m} / \mathrm{s}$ dengan index 4 , Jitter sebesar $12.92 \mathrm{~m} / \mathrm{s}$ dengan index 3, Packet loss $0 \%$ dengan index 4, dan Throughput $100 \%$ dengan index 4, sehingga secara keseluruhan dari parameter QoS di FTI UKSW dapat disimpulkan Sangat Memuaskan.

a. Delay

Tabel 8. Analisa parameter delay

\begin{tabular}{cccc}
\hline $\begin{array}{c}\text { Paket } \\
\text { Data }\end{array}$ & Total Delay & $\begin{array}{c}\text { Total paket } \\
\text { diterima }\end{array}$ & Index \\
\hline 1 & $9.365275 \mathrm{~m} / \mathrm{s}$ & $3.976476 \mathrm{~m} / \mathrm{s}$ & 4 \\
2 & $9.405166 \mathrm{~m} / \mathrm{s}$ & $9.365275 \mathrm{~m} / \mathrm{s}$ & 4 \\
3 & $9.405269 \mathrm{~m} / \mathrm{s}$ & $9.405166 \mathrm{~m} / \mathrm{s}$ & 4 \\
4 & $9.405434 \mathrm{~m} / \mathrm{s}$ & $9.405269 \mathrm{~m} / \mathrm{s}$ & 4 \\
5 & $9.431064 \mathrm{~m} / \mathrm{s}$ & $9.405434 \mathrm{~m} / \mathrm{s}$ & 4 \\
\hline
\end{tabular}


Pada Tabel 8 di atas adalah hasil pengukuran dari delay. Dari hasil pengukuran total delay yang paling tinggi sebesar $9.431064 \mathrm{~m} / \mathrm{s}$ dan hasil ini terbilang Sangat Memuaskan, lalu untuk hasil terendah delay sebesar $3.976476 \mathrm{~m} / \mathrm{s}$. Sehingga dapat disimpulkan bahwa nilai rata-rata delay WLAN FTI UKSW yaitu $<150 \mathrm{~m} / \mathrm{s}$, dengan index TIPHON 4 atau Sangat Memuaskan. Untuk melihat perhitungan dalam grafik dapat di lihat di Gambar 4.

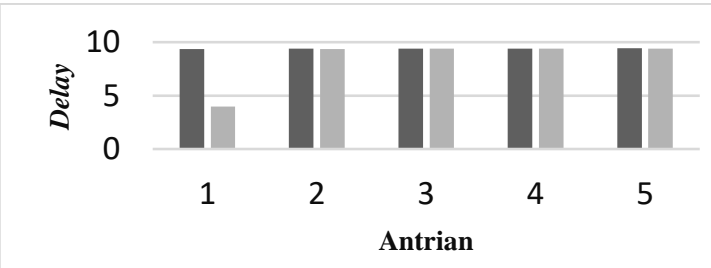

- Total Delay $\quad$ Total Paket Diterima

Gambar 4. Grafik Delay

b. Jitter

Proses selanjutnya dilakukan analisis jitter sebagaimana ditunjukkan pada Tabel 9.

\begin{tabular}{cccc}
\multicolumn{4}{c}{ Tabel 9. Analisa parameter jitter } \\
\hline $\begin{array}{c}\text { Paket } \\
\text { Data }\end{array}$ & $\begin{array}{c}\text { Total variasi } \\
\text { jitter }\end{array}$ & $\begin{array}{c}\text { Total paket } \\
\text { diterima }\end{array}$ & Index \\
\hline 1 & $0.039891 \mathrm{~m} / \mathrm{s}$ & $5.388799 \mathrm{~m} / \mathrm{s}$ & 3 \\
2 & $0.000103 \mathrm{~m} / \mathrm{s}$ & $0.039891 \mathrm{~m} / \mathrm{s}$ & 4 \\
3 & $0.000165 \mathrm{~m} / \mathrm{s}$ & $0.000103 \mathrm{~m} / \mathrm{s}$ & 4 \\
4 & $0.02563 \mathrm{~m} / \mathrm{s}$ & $0.000165 \mathrm{~m} / \mathrm{s}$ & 4 \\
5 & $0 \mathrm{~m} / \mathrm{s}$ & $0.02563 \mathrm{~m} / \mathrm{s}$ & 4 \\
\hline
\end{tabular}

Pada Tabel 9 di atas adalah hasil akhir dari perjalanan paket yang diterima dari jaringan IP. Paket data 1 dan 5 rata-rata nilai total variasi delay adalah $0.032 \mathrm{~m} / \mathrm{s}$, kemudian rata-rata paket yang di terima adalah $2.727 \mathrm{~m} / \mathrm{s}$. Sehingga dapat disimpulkan bahwa nilai rata-rata jitter WLAN FTI UKSW yaitu $0 \mathrm{~m} / \mathrm{s}$ $75 \mathrm{~m} / \mathrm{s}$, dengan index 3 atau Memuaskan. Untuk melihat perhitungan dalam grafik dapat di lihat di Gambar 5.

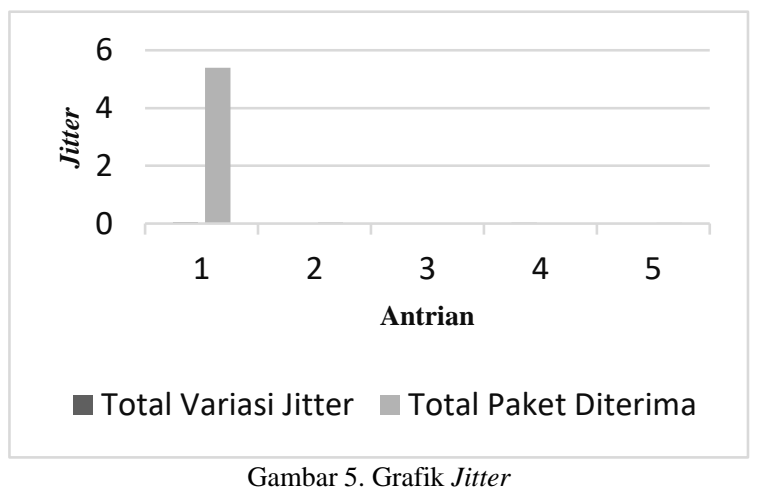

c. Packet Loss

Tahapan berikutnya adalah dilakukan Analisa packet loss. Adapun hasilnya ditunjukkan pada Tabel 10.
Tabel 10. Analisa parameter packet loss

\begin{tabular}{ccc}
\hline Paket data & Packet Loss & Index \\
\hline 1 & 0 & 4 \\
2 & 0 & 4 \\
3 & 0 & 4 \\
4 & 0 & 4 \\
5 & 0 & 4 \\
\hline
\end{tabular}

Pada Tabel 10 di atas adalah hasil packet loss yang di analisa dengan menggunakan wireshark selama 30 detik. Hasil menunjukkan tidak ada paket yang hilang selama analisa dikarenakan bandwidth yang tersedia cukup dan tidak ada penumpukan paket yang berarti. Sehingga dapat disimpulkan bahwa nilai packet loss WLAN FTI UKSW yaitu $0 \%$, dengan index 4 atau Sangat Memuaskan. Hasil dari packet loss ada pada Gambar 6.

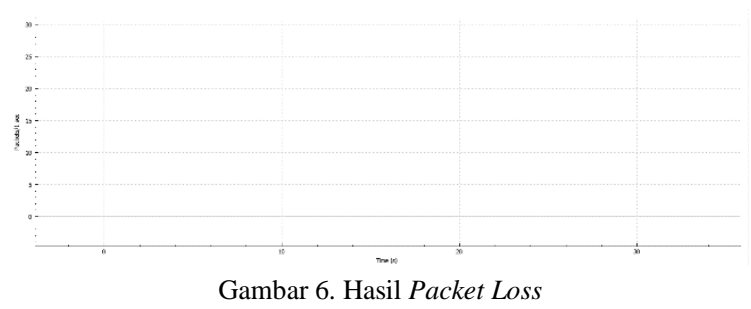

\section{d. Throughput}

Setelah packet loss didapatkan selanjutnya dianalisa throughput, sebagaimana hasilnya ditunjukkan pada Gambar 7.

Statistics

$\begin{array}{lll}\text { Measurement } & \text { Captured } & \text { Displayed } \\ \text { Packets } & 4040 & 4040(100.0 \%) \\ \text { Time span, s } & 27.678 & 27.678 \\ \text { Average pps } & 146.0 & 146.0 \\ \text { Average packet size, B } & 233 & 233 \\ \text { Bytes } & 941169 & 941169(100.0 \%) \\ \text { Average bytes/s } & 34 \mathrm{k} & 34 \mathrm{k} \\ \text { Average bits/s } & 272 \mathrm{k} & 272 \mathrm{k}\end{array}$

Gambar 7. Hasil Throughput

Pada Gambar 7 di atas adalah hasil throughput yang di analisa dengan menggunakan wireshark selama 30 detik. Berikut hasil pengukuran throughput beserta dengan hasil di bawah.

$$
\begin{aligned}
\text { Throughput }= & \text { Paket data yang diterima }(\mathrm{kb}) \\
& =\frac{941169 \mathrm{~kb}}{27.678 \mathrm{~s}} \\
& =34.004 .22 \mathrm{~kb} / \mathrm{s} \times 8 \\
& =272 \mathrm{~kb} / \mathrm{s}
\end{aligned}
$$

Berdasarkan pengukuran throughput di atas untuk paket data yang diterima sebesar $941169 \mathrm{~kb}$ lalu dibagi dengan lama pengamatan $27.678 s$ dan mendapat hasil 34.004.22 kb/s, kemudian $\times 8$ dan mendapatkan hasil sebesar $272 \mathrm{~kb} / \mathrm{s}$. Sehingga dapat disimpulkan bahwa nilai rata-rata throughput WLAN FTI UKSW yaitu $100 \%$, dengan indeks 4 atau Sangat Memuaskan, karena statistics rata-rata bits/s antara captured dengan displayed sama. 


\subsection{Hasil Total Delay dan Jitter}

Di bawah ini adalah hasil pengukuran total delay dan jitter dimana total delay yang telah di analisa selama 30 detik menggunakan wireshark menunjukkan hasil total delay sebesar 23.701949 $\mathrm{m} / \mathrm{s}$, dan rata-rata delay $0.005868272 \mathrm{~m} / \mathrm{s}$. Untuk hasil total jitter sebesar $12.924351 \mathrm{~m} / \mathrm{s}$, dan rata-rata jitter $0.003199889 \mathrm{~m} / \mathrm{s}$. Untuk tampilan dalam grafik dapat di lihat pada Gambar 8.

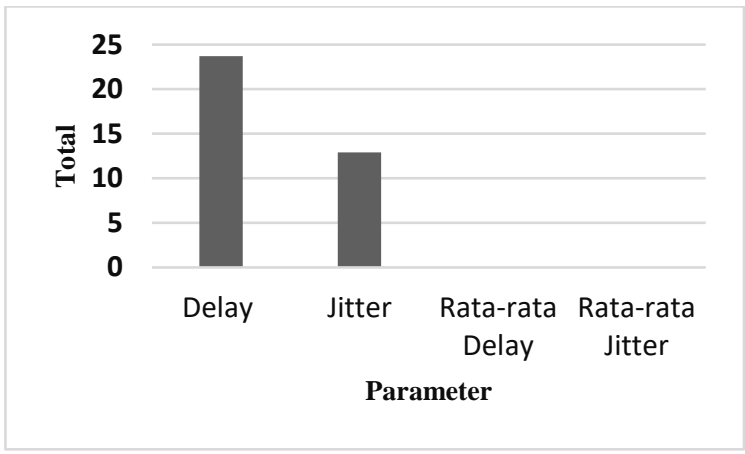

Gambar 8. Hasil total delay dan jitter

\section{KESIMPULAN}

Berdasarkan Analisa Quality of Service menggunakan metode Hierarchical Token Bucket yang sudah dilakukan, maka dapat disimpulkan bahwa setiap parameter kualitas jaringan mulai dari Delay, Jitter, Packet loss, dan Throughput mampu dalam menerapkan metode manajemen bandwidth HTB. Dengan adanya manajemen bandwidth ini user dapat merasakan kepuasan di dalam melakukan proses pertukaran data dan berbagi informasi untuk mendapatkan performa yang optimal. Sehingga dapat disimpulkan bahwa Analisa Quality of Service menggunakan metode Hierarchical Token Bucket di Fakultas Teknologi Informasi Universitas Kristen Satya Wacana memiliki nilai yang Sangat Memuaskan dan tidak mengecewakan.

\section{DAFTAR PUSTAKA}

[1] A. Armanto and N. K. Daulay. 2020. "Analisis Quality of Service (Qos) Pada Jaringan Internet Di Universitas Bina Insan Lubuklinggau Menggunakan Metode Hierarchical Token Bucket (Htb)," J. Digit. Teknol. Inf., vol. 3, no. 1, p. 8.

[2] C. P. Antodi, A. B. Prasetijo, and E. D. Widianto. 2017. "Penerapan Quality of Service Pada Jaringan Internet Menggunakan Metode Hierarchical Token Bucket," J. Teknol. dan Sist. Komput., vol. 5, no. 1, p. 23.

[3] M. Iqbal Ichwan, L. Sugiyanta, and P. Wibowo Yunanto. 2019. "Analisis Manajemen Bandwidth Hierarchical Token Bucket (HTB) dengan Mikrotik pada Jaringan SMK Negeri 22," PINTER J. Pendidik. Tek. Inform. dan Komput., vol. 3, no. 2, pp. 122-126.
[4] M. R. Dirgantara, I. Asrowardi, and E. W. Kenali. 2019. "Perancangan Dan Implementasi Bandwidth Management Pesawaran,” pp. 1-5.

[5] A. Wahyu Azinar and R. Sapta Adi. 2017. "Analisis QoS (Quality of Service) pada Warnet dengan Metode HTB (Hierarchical Token Bucket)," J. Ilm. Nero, vol. 3, no. 1, pp. 45-52.

[6] S. Ahdan, O. Firmanto, and S. Ramadona. 2018. "Rancang Bangun dan Analisis QoS (Quality of Service) Menggunakan Metode HTB (Hierarchical Token Bucket) pada RT/RW Net Perumahan Prasanti 2," J. Teknoinfo, vol. 12, no. 2 , p. 49.

[7] A. Diyantoro and H. Haekal. 2018. "Penerapan Manajemen Bandwidth Menggunakan Hierarchical Token Bucket Pada,".

[8] S. Budin and I. Riadi. 2019. "Traffic Shaping Menggunakan Metode HTB (Hierarchical Token Bucket) pada Jaringan Nirkabel," Bul. Ilm. Sarj. Tek. Elektro, vol. 1, no. 3, p. 144.

[9] Aprianto Budiman, M. Ficky Duskarnaen, and Hamidillah Ajie. 2020. "Analisis Quality of Service (Qos) Pada Jaringan Internet Smk Negeri 7 Jakarta," PINTER J. Pendidik. Tek. Inform. dan Komput., vol. 4, no. 2, pp. 32-36.

[10] Y. A. Pranata, I. Fibriani, and S. B. Utomo. 2016. "Analisis Optimasi Kinerja Quality of Service Pada Layanan Komunikasi Data Menggunakan Ns-2 Di Pt. Pln (Persero) Jember," Sinergi, vol. 20, no. 2, p. 149.

[11] N. S. Abdullah, A. Fuad, and M. Jamil. 2019. "Penerapan Metode Simple Queue Pada Manajemen Bandwith untuk mengoptimalkan Bandwith Di Laboratorium Program Studi Teknik Informatika," JIKO (Jurnal Inform. dan Komputer), vol. 2, no. 1, pp. 6-13.

[12] A. A. Zuqhra and N. R. Rosyid. 2021. "Implementasi dan Analisis Metode Hierarchical Token Bucket dan Per Connection Queue pada Jaringan Multi Protocol Label Switching Traffic Engineering untuk Layanan Voice over Internet Protocol," J. Telekomun., vol. 4, pp. 465-477.

[13] Sutarti, Siswanto, and A. Subandi. 2018. "Implementasi Dan Analisis QoS (Quality of Service) Pada VoIP (Voice Over Internet Protocol) Berbasis Linux," J. PROSISKO, vol. 5, no. 2, pp. 92-101.

[14] G. Ardiansa and R. Primananda. 2017. "Manajemen Bandwidth dan Manajemen Pengguna pada Jaringan Wireless Mesh Network dengan Mikrotik," J. Pengemb. Teknol. Inf. dan Ilmu Komput., vol. 1, no. 11, p. 47.

[15] I. Solikin. 2017. "Penerapan Metode PPDIOO Dalam Pengembangan LAN Dan WLAN," Teknomatika, vol. 07, no. 01, pp. 65-73. 